\title{
A tool for the interactive analysis and exploration of in-vivo haemodynamics from 4D PC MRI
}

\author{
Johann B Drexl ${ }^{1 *}$, Anja Hennemuth', Sebastian Meier ${ }^{1}$, Ramona Lorenz ${ }^{2}$, Jelena Bock², Andreas Harloff ${ }^{4}$, \\ Michael Markl ${ }^{3}$, Horst K Hahn ${ }^{1}$ \\ From 15th Annual SCMR Scientific Sessions \\ Orlando, FL, USA. 2-5 February 2012
}

\section{Background}

Time-resolved 3D (4D) phase contrast (PC) MRI allows deriving anatomical as well as functional information in the cardiovascular system. Progress in 4D MR techniques now facilitates volumetric, 3-directional, cine PC MRI data in reasonable scan times. The analysis of these data is, however, a challenging task because of the data complexity ( 3 spatial dimensions, 3 velocity directions, time) and the many processing steps required. Current evaluations of 4D PC MRI data often use a combination of home built and commercial tools, which are tailored to often time consuming (up to several hours) workflows for special research questions. The purpose of this study was to develop and evaluate a novel analysis tool that allows a fast interactive exploration of patient-specific 4D-PC hemodynamics.

\section{Methods}

The tool provides a combination of pre-processing and analysis methods including 4D phase offset error correction with 3rd order polynomials, antialiasing to correct of phase wraps, semi-automatic vessel segmentation, 3D flow visualization, and calculations of $4 \mathrm{D}$ pressure difference maps within the vessel volume. Based on this information, mean velocities and flow rates are calculated at user-defined cross sections of the vessel. Forward as well as backward tracking of pathlines emitted from user defined regions allows the visualization of flow pathways, which can be color-coded according to local velocity, direction, curvature or their emitter region (Fig 1).

'Fraunhofer MEVIS, Bremen, Germany

Full list of author information is available at the end of the article

\section{Results}

Experts with different clinical specialization analyzed a total of 11 cases (thoracic as well as cranial datasets). The evaluation consisted of the segmentation of the vessels of interest, animated visualizations of flow pathways, placement of several regions of interest, inspection and export of quantitative measurements of velocity and flow. The average processing times were $35.3 \mathrm{~min}$ $+/-14.4 \mathrm{~min}$ for the thoracic datasets and $45.2 \mathrm{~min}$ $+/-11.1$ min for the cranial datasets.

In addition, our clinical partners provided us with Doppler ultrasound measurements for 5 additional aortical cases with aortic coarctation, which we utilized for an assessment of the velocity estimation functionality in our tool. The 4D PCMRI datasets of these patients were analyzed using our tool, and measurements of peak velocity were performed at cross sections placed in the coarctation.

We found a correlation coefficient of $\mathrm{r}=0.90$ between the peak velocities measured by Doppler and the peak velocities computed by our tool from PC MRI data(Fig 2).

\section{Conclusions}

We presented a software tool that provides the improved functionality for the analysis and exploration of 4D PC MRI data including pre-processing, segmentation, quantification and visual exploration of flow patterns. We demonstrated the usability of our tool by clinical experts, and we presented a comparison with the clinically accepted Doppler ultrasound method.

\section{Funding}

Funded by the Deutsche Forschungsgemeinschaft project "Plaques der Aorta als Emboliequelle für Schlaganfälle" FR 2795/2-1. 


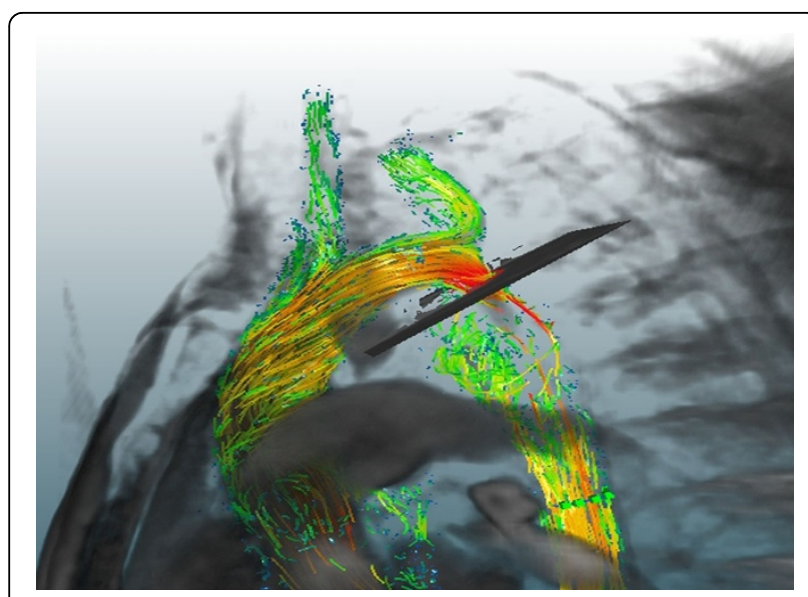

Figure 1 Visualization of flow pathways

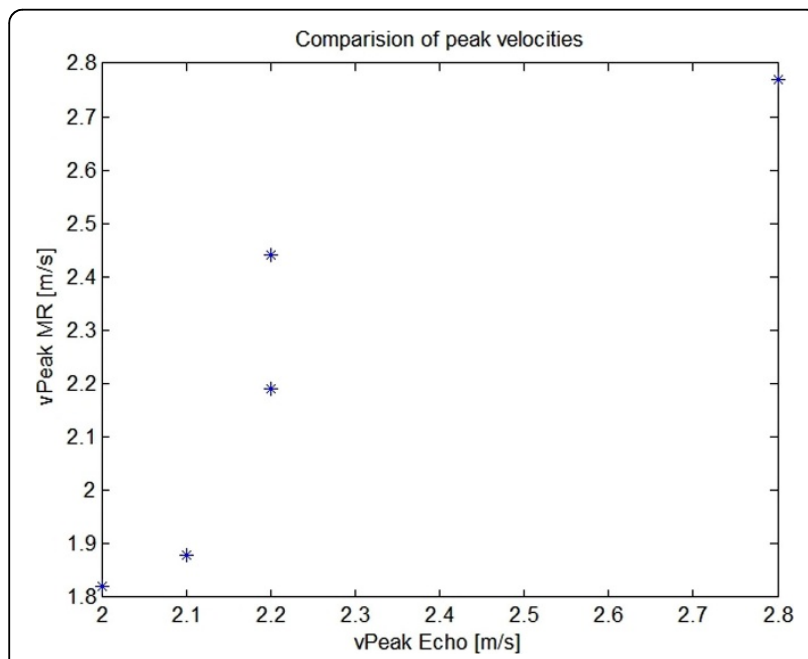

Figure 2 Comparision of peak velocities measured by Doppler and by MRI

\section{Author details}

${ }^{1}$ Fraunhofer MEVIS, Bremen, Germany. ${ }^{2}$ Department of Radiology, Medical Physics, University Medical Center Freiburg, Freiburg, Germany. ${ }^{3}$ Departments of Radiology and Biomedical Engineering, Northwestern University Feinberg School of Medicine, Chicago, IL, USA. ${ }^{4}$ Neurology, Universitätsklinik Freiburg, Freiburg, Germany.

Published: 1 February 2012

doi:10.1186/1532-429X-14-S1-W70

Cite this article as: Drexl et al: A tool for the interactive analysis and exploration of in-vivo haemodynamics from 4D PC MRI. Journal of

Cardiovascular Magnetic Resonance 2012 14(Suppl 1):W70.

\section{Submit your next manuscript to BioMed Central} and take full advantage of:

- Convenient online submission

- Thorough peer review

- No space constraints or color figure charges

- Immediate publication on acceptance

- Inclusion in PubMed, CAS, Scopus and Google Scholar

- Research which is freely available for redistribution

Submit your manuscript at www.biomedcentral.com/submit
C Biomed Central 